\title{
Universidade do Minho livre de tabaco: uma nova realidade
}

Inês Marques, ${ }^{*}$ Isabel Silva, ${ }^{* *}$ Marlene Abreu, ${ }^{* * *}$ Viviana Azevedo, ${ }^{* * * *}$ Mário Freitas*****

\section{RESUMO}

Objectivos: caracterizar o padrão de consumo de tabaco dos alunos da Universidade do Minho (UM); determinar conhecimentos e comportamentos face ao tabaco e à Lei n. ${ }^{\circ} 37 / 2007$; conhecer a opinião acerca da aplicação desta lei na UM e o impacto no consumo e qualidade do ar interior.

Tipo de estudo: estudo descritivo transversal.

Local: UM, pólo de Gualtar - Braga.

População: alunos inscritos em licenciaturas ou mestrados integrados da UM, no ano lectivo 2007/2008.

Métodos: foi aplicado um questionário a uma amostra de conveniência de 334 indivíduos do total de 9028 alunos inscritos. Foi utilizada a prova de $\chi$-quadrado e um nível de significância de 0,05 .

Resultados: dos alunos inquiridos, $62 \%$ já experimentaram consumir tabaco, 5,8\% dos quais o fizeram na universidade. Na amostra, $27,9 \%$ dos alunos eram fumadores, sendo que, destes, $51,6 \%$ consumia entre um e 10 cigarros/dia e $13 \%$ fumava mais de 20 cigarros/dia. A maioria afirmou não fumar em locais públicos fechados e na UM fumar ao ar livre. Os alunos apresentaram bom nível de conhecimentos relativamente ao impacto do tabaco na saúde, sendo este menor nos fumadores e naqueles que já experimentaram consumir. A maioria dos inquiridos sabia da existência de legislação que proíbe consumo de tabaco em certos locais; $96,1 \%$ concordava com a proibição do consumo nos espaços fechados da UM e esta opinião dependia de ser fumador, pois foi entre estes que houve quem discordasse da medida. Na opinião de 91,3\% dos inquiridos, o ambiente dos espaços fechados da UM melhorou com a proibição de fumar. Com esta lei, a maioria passou a fumar apenas ao ar livre, $45,2 \%$ diminuiu o seu consumo e $24,7 \%$ deixou de fumar.

Conclusões: A lei do tabaco parece estar a contribuir para a diminuição do número de fumadores e para a protecção dos não fumadores do fumo de tabaco.

Palavras-Chave: tabagismo, legislação, estudantes, educação superior.

\section{INTRODUÇÃO}

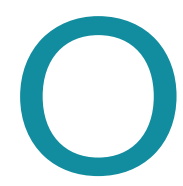

consumo de tabaco é considerado a principal causa isolada e evitável de doença e morte no mundo ocidental. Em 2008, segundo estimativas da Organização Mun-

*Interna de Formação Específica de Pediatria do Centro Hospitalar do Barreiro-Montijo, Mestre em Medicina graduada na Escola de Ciências da Saúde da Universidade do Minho.

**Interna de Formação Específica de Medicina Interna do Hospital de Braga, Mestre em Medicina graduada na Escola de Ciências da Saúde da Universidade do Minho.

***Interna de Formação Específica de Pediatria da Unidade Local de Saúde de Matosinhos, Mestre em Medicina graduada na Escola de Ciências da Saúde da Universidade do Minho.

****Interna de Formação Específica de Urologia do Hospital de São João - Porto, Mestre em Medicina graduada na Escola de Ciências da Saúde da Universidade do Minho.

*****Médico de Saúde Pública da Unidade de Saúde Pública de Braga, Professor convidado do Departamento de Saúde Comunitária da Escola de Ciências da Saúde da Universidade do Minho. dial de Saúde (OMS), era responsável pela morte de cerca de 5 milhões de pessoas anualmente, ${ }^{1}$ o que significa que vitimava mais do que a SIDA, as drogas ilegais, os acidentes de viação, os homicídios e os suicídios em conjunto. ${ }^{2} \mathrm{Na}$ verdade, e de acordo com estudos sobre a mortalidade associada ao tabaco ao nível dos países desenvolvidos entre 1950 e 2000, estima-se que a cada 10 segundos uma pessoa morre devido a doenças relacionadas com o consumo de tabaco. ${ }^{3}$ Fumar constitui, por isso, um grave problema de saúde pública à escala mundial, nacional e local, enquanto agressão ao próprio, ao próximo e ao ambiente.

Em 2001 a OMS estimava que um terço da população mundial era fumadora. ${ }^{4}$ Em Portugal Continental, em 2005, a prevalência de fumadores na população era de $27 \%,{ }^{5}$ tendo diminuído para $24 \%$ em $2006 .{ }^{6}$ Estudos epi- 
demiológicos a nível nacional mostram ainda que, ao contrário do que acontece nos restantes países desenvolvidos, onde o consumo tabágico se inicia maioritariamente até aos 18 anos de idade, em Portugal o consumo regular de tabaco ocorre mais tardiamente: $39 \%$ dos fumadores iniciam o hábito de fumar entre os 18 e os 24 anos, o que demonstra que muitos fumadores começam a fumar após a admissão no ensino universitário. ${ }^{7,8}$

O tabaco, principal poluente evitável do ar interior, é classificado como um carcinogénio humano de $1 .^{\circ}$ grau, para o qual não é possível estabelecer um limiar seguro de exposição. ${ }^{9}$ Assim se depreende o elevado impacto do consumo de tabaco na saúde bem como a necessidade de definir uma política de gestão ambiental e regulamentação do comportamento de fumar, que não estigmatize os fumadores, mas proteja a saúde de todos, ao minimizar a exposição ao fumo de tabaco ambiental. ${ }^{10}$ Em Portugal, embora existissem algumas medidas alusivas a esta temática no Plano Nacional de Saúde 2004/2010, só recentemente foi aprovada a Lei n. ${ }^{0} 37 / 2007$, de 14 de Agosto, ${ }^{11}$ que, pretendendo dar execução ao disposto na Convenção Quadro da OMS para o Controlo do Tabaco, ${ }^{12}$ visa estabelecer normas referentes à protecção da exposição involuntária ao fumo do tabaco, de modo a contribuir para a diminuição dos riscos ou efeitos negativos que o uso do tabaco acarreta para a saúde dos indivíduos.

Diversos estudos demonstram que medidas semelhantes a esta lei são efectivas na promoção da cessação e na redução do número de cigarros consumidos por dia, particularmente entre os estudantes universitários. ${ }^{10,13,14}$ Perante a escassez de dados e de estudos publicados em Portugal e a noção de que é na universidade que grande parte dos consumos se iniciam, surgiu o presente estudo, com o objectivo de caracterizar o padrão de consumo e outro tipo de comportamentos face ao tabaco dos alunos da Universidade do Minho (UM), avaliar o seu nível de conhecimentos sobre o impacto do tabaco na saúde e sobre a Lei n. ${ }^{\circ} 37 / 2007$, de 14 de Agosto, conhecer a sua opinião acerca da aplicação desta lei na UM e do seu impacto no consumo de tabaco e na qualidade do ar interior.

\section{MÉTODOS}

Tratou-se de um estudo descritivo com um componente analítico. Os dados foram recolhidos através de um inquérito por questionário de auto-preenchimento maioritariamente com questões fechadas pré-codificadas, à excepção dos dados sócio-demográficos que foram inquiridos através de algumas questões abertas (anexo 1). Na bibliografia consultada não foi possível a obtenção de um instrumento de inquirição que se adequasse de forma integral ao tema e objectivos deste trabalho. Por esta razão, foi elaborado pelos autores um questionário que incluiu, quer questões provenientes de questionários de estudos anteriores, quer algumas questões originais. Foi efectuado um pré-teste através da aplicação do questionário a 50 estudantes da Faculdade de Medicina da Universidade do Porto.

A população em estudo era constituída pelos alunos matriculados em licenciaturas ou mestrados integrados da UM, pólo de Gualtar - Braga, no ano lectivo 2007/2008 (n=9028). Para um intervalo de confiança de 95\% e uma precisão desejada de $5 \%$ foi planeada uma amostra mínima de 312 alunos, tendo sido definidos quatro estratos na população, cuja proporção foi respeitada no cálculo da amostra. Assim, os «cursos da área de saúde» correspondiam a 7,2\% (n=646), 0 «curso de Psicologia» a 5,2\% (n=466), os «cursos a área de educação/ensino" a 11,2\% ( $\mathrm{n}=1013)$ e os "outros cursos» a 76,5\% ( $n=6903)$. Os alunos do sexo feminino correspondiam a 58,0\% (n=5241) e os do sexo masculino a $42,0 \%$ ( $n=3787$ ) do total da população. Contando, quer com a recusa de participação por parte de alguns alunos, quer com a invalidação de alguns questionários por preenchimento incorrecto, foi aumentado o tamanho da amostra para 450 alunos.

Não foi possível efectuar uma amostragem aleatória porque os serviços académicos da UM não disponibilizaram os dados individuais de todos os alunos matriculados por serem confidenciais. Assim sendo, foi efectuada uma amostragem de conveniência. Com base na listagem fornecida, que continha apenas informação geral sobre o total de alunos inscritos por curso, ano de curso e sexo, foram seleccionados aleatoriamente anos de cursos dentro de cada estrato até perfazer o número mínimo de indivíduos calculado para a amostra. $\mathrm{O}$ questionário foi aplicado em Abril de 2008 aos alunos dos anos de curso seleccionados no início ou final de uma aula, após breve apresentação do trabalho e explicação do que era pretendido, salvaguardando sempre o facto de que o preenchimento do questionário era 
voluntário e anónimo. Após o preenchimento, os alunos introduziram o questionário numa caixa fechada tipo urna, que só foi aberta no final da aplicação dos questionários à totalidade da amostra.

Após análise de todos os questionários, foram excluídos aqueles que apresentaram incorrecções no seu preenchimento, tais como: múltiplas respostas em questões de resposta única, questões por preencher, respostas rasuradas que tornaram difícil a identificação da opção assinalada ou não preenchimento dos dados pessoais. Todas as respostas dos questionários validados foram de seguida introduzidas numa base de dados do programa informático SPSS $®$, versão 16.0, para a sua análise estatística. Para verificar a existência de relação entre duas variáveis qualitativas recorreu-se à Prova do Qui-Quadrado. O nível de significância estatística considerado foi de 0,05 .

\section{RESULTADOS}

Dos 450 questionários distribuídos, 420 foram preenchidos, o que perfaz uma taxa de respostas de $93,3 \%$. Foram excluídos 86 questionários por incorrecções no preenchimento, tendo, assim, a amostra final ficado constituída por 334 indivíduos: 8,7\% (n=29) do estrato «cursos da área de Saúde», 6,3\% (n=21) do estrato «Curso de Psicologia", $13,5 \%(n=45)$ do estrato "cursos da área de Educação/Ensino»e 71,5\% (n=239) do estrato «Outros cursos».

Do total de alunos respondentes, $68,6 \%$ eram do sexo feminino e $31,4 \%$ do masculino. A idade dos indivíduos variou entre os 18 e os 46 anos, com uma média de 21,4 $( \pm 4)$ anos.

\section{Padrão de Consumo}

Dos alunos respondentes, $62,0 \%$ já tinham experimentado consumir tabaco. Relativamente à idade da primeira experiência de consumo de tabaco, 51,6\% tiveram-na antes dos 15 anos, 44,9\% entre os 15 e os 18 anos e 5,8\% na universidade. Do total de respondentes, $27,9 \%$ eram fumadores. Destes, $14,7 \%$ foram considerados fumadores regulares (consumo de tabaco pelo menos uma vez por dia) e 13,2\% fumadores ocasionais (consumo de tabaco pelo menos uma vez por semana, por mês ou por ano). Houve ainda $34,1 \%$ dos respondentes que consumiam tabaco «menos de uma vez por ano», constituindo provavelmente fumadores experimentais ou ex-fumadores e, por isso, neste estudo serão referidos adiante como não fumadores actuais (quadro I).

Analisando a população fumadora por sexo, 18,1\% dos indivíduos do género feminino fumava regularmente, para $35,3 \%$ dos indivíduos do género masculino. No que diz respeito ao consumo ocasional de tabaco, a situação inverte-se: menos alunos eram fumadores ocasionais $(11,4 \%)$ comparativamente a alunas (14\%).

Considerando os respondentes que consomem tabaco, 51,6\% afirmou fumar entre 1 e 10 cigarros/dia, enquanto $13 \%$ fumava mais de 20 cigarros/dia.

No que se refere aos locais de consumo, $49,5 \%$ dos indivíduos refere fumar em casa, $51,6 \%$ em bares e/ ou discotecas e $39,8 \%$ em cafés e/ ou restaurantes (quadro II). Para além disto, 81,7\% afirmou não fumar em locais públicos fechados.

Relativamente aos locais utilizados pelos respondentes para fumarem na UM, 59,1\% afirmou fumar apenas ao ar livre e $36,6 \%$ não fumava na UM. Curiosamente, $4,3 \%$ afirmou fumar em áreas fechadas expressamente previstas para o efeito, que embora estejam previstas na legislação, não foram ainda criadas na UM.

Uma pequena minoria $(5,4 \%)$ dos fumadores admitiu fumar em locais onde não é permitido e $82,8 \%$ afirmaram abster-se de fumar na presença de indivíduos não fumadores pelo menos «às vezes».

Por último, $36,5 \%$ dos respondentes nunca tentaram deixar de fumar, $24,7 \%$ já tentaram mas sem sucesso e $22,6 \%$ já deixaram de fumar e não fumam neste momento.
QUADRO I. Frequência de consumo de tabaco.

\begin{tabular}{|c|c|c|c|c|}
\hline \multirow{3}{*}{$\begin{array}{l}\text { Frequência de consumo } \\
\text { de tabaco } \\
\text { Pelo menos } 1 \mathrm{vez} / \mathrm{dia}\end{array}$} & \multicolumn{2}{|c|}{ Frequência } & \multirow{2}{*}{\multicolumn{2}{|c|}{$\begin{array}{l}\text { Percentagem } \\
\text { cumulativa (\%) }\end{array}$}} \\
\hline & \multirow{2}{*}{$\begin{array}{c}n \\
49\end{array}$} & \multirow{2}{*}{$\begin{array}{c}\% \\
14,7\end{array}$} & & \\
\hline & & & & 27,9 \\
\hline Pelo menos 1 vez/semana & 11 & 3,3 & 13,2 & \\
\hline Pelo menos 1 vez/mês & 12 & 3,6 & & \\
\hline Pelo menos 1 vez/ano & 21 & 6,3 & & \\
\hline Menos de 1 vez/ano & 114 & 34,1 & & \\
\hline Nunca & 127 & 38,0 & & \\
\hline
\end{tabular}


QUADRO II. Locais de consumo de tabaco dos alunos da UM.

\begin{tabular}{l|l|c} 
& & Frequência (\%) \\
\hline Locais de consumo & Em casa & 49,5 \\
\cline { 2 - 3 } & Universidade do Minho & 33,3 \\
\cline { 2 - 3 } & Local de trabalho & 7,5 \\
\cline { 2 - 3 } & Cafés e/ou restaurantes & 39,8 \\
\cline { 2 - 3 } & Bares e/ou discotecas & 51,6 \\
\cline { 2 - 3 } & Todas as anteriores & 1,1 \\
\cline { 2 - 3 } & Nenhuma das anteriores & 8,6 \\
\hline
\end{tabular}

\section{Outros comportamentos face ao tabaco}

A frequência com que os respondentes se sentem incomodados com o fumo do tabaco pelo menos às vezes foi de $84,6 \%$ (quadro III). Isto pareceu estar associado com o padrão de consumo de tabaco (quadro IV), já que a frequência de respondentes considerados não fumadores actuais que referiu sentir-se incomodado com o fumo de tabaco pelo menos «às vezes» foi de $94,7 \%$, enquanto a relativa aos alunos que fumam de forma regular ou ocasional foi menor (45,4 a 76,2\%), diferença esta estatisticamente significativa $(p<0,0001)$. Da totalidade dos alunos respondentes, 59,9\% afirmaram abandonar locais onde é permitido consumir tabaco pelo menos «às vezes», quando se sentem incomodados pelo fumo do cigarro (quadro III). Este valor pareceu estar associado ao padrão de consumo de tabaco (quadro IV), visto que a frequência de respondentes que referiu abandonar esses locais pelo menos às vezes foi maior no grupo dos não fumadores actuais (62\%) relativamente aos fumadores regulares $(18,4 \%)$ e ocasionais $(27,3 \%$ a $42,9 \%$ ), diferença esta estatisticamente significativa ( $p<0,0001)$. Nas mesmas circunstâncias, só 31,8\% dos respondentes afirmaram pedir ao fumador para não fumar ou para não o fazer perto de si pelo menos «às vezes» (quadro III). Por outro lado, quando se encontram em locais onde nãoé permitido consumir tabaco, $41,7 \%$ dos respondentes afirmaram abandonar o local pelo menos «às vezes», tendo a maioria $(58,3 \%)$ respondido «raramente» ou «nunca». Nestes locais, $60,7 \%$ dos respondentes afirmaram pedir a fumadores para não fumarem, ou para não o fazerem perto de si, pelo menos «às vezes», valor que é bastante superior aos $31,8 \%$ de indivíduos que o fazem em locais onde é permitido fumar (quadro III). Nos locais onde não é permitido fumar, a frequência de indivíduos do género masculino que pedem «sempre» $(28,6 \%)$ a fumadores para não fumarem ou para não o fazerem perto deles foi significativamente maior $(p=0,046)$ que a relativa ao género feminino $(20,5 \%)$, tendo a resposta contrária, «nunca», um resultado controverso: $24,8 \%$ dos homens contra $15,3 \%$ das mulheres (quadro $\mathrm{V}$ ).

A maioria (94,3\%) dos alunos demonstrou que «concordam completamente» ou «concordam» com a afirmação «os não fumadores têm o direito de respirar ar livre de fumo de tabaco».

QUADRO III. Comportamentos dos alunos da UM face ao tabaco.

\begin{tabular}{|c|c|c|c|c|c|c|c|c|c|c|}
\hline \multirow[b]{2}{*}{ Sempre } & \multicolumn{2}{|c|}{$\begin{array}{c}\text { Sentir-se } \\
\text { incomodado pela } \\
\text { exposição ao fumo } \\
\text { de tabaco }\end{array}$} & \multicolumn{2}{|c|}{$\begin{array}{l}\text { Abandono de um } \\
\text { local onde é } \\
\text { permitido fumar, } \\
\text { por se sentir } \\
\text { incomodado com o } \\
\text { fumo de tabaco }\end{array}$} & \multicolumn{2}{|c|}{$\begin{array}{l}\text { Pedir a um fumador } \\
\text { para não fumar num } \\
\text { local onde é } \\
\text { permitido }\end{array}$} & \multicolumn{2}{|c|}{$\begin{array}{l}\text { Abandono de um } \\
\text { local onde não é } \\
\text { permitido fumar, } \\
\text { por se sentir } \\
\text { incomodado com o } \\
\text { fumo de tabaco }\end{array}$} & \multicolumn{2}{|c|}{$\begin{array}{l}\text { Pedir a um fumador } \\
\text { para não fumar num } \\
\text { local onde não é } \\
\text { permitido }\end{array}$} \\
\hline & $30,5 \%$ & \multirow{3}{*}{$84,6 \%$} & $6,6 \%$ & \multirow{3}{*}{$59,9 \%$} & $3,6 \%$ & \multirow{3}{*}{$31,8 \%$} & $9,3 \%$ & \multirow{3}{*}{$41,7 \%$} & $23,0 \%$ & \multirow{3}{*}{$60,7 \%$} \\
\hline Frequentemente & $25,1 \%$ & & $20,1 \%$ & & $7,2 \%$ & & $11,7 \%$ & & $17,0 \%$ & \\
\hline Às vezes & $29,0 \%$ & & $33,2 \%$ & & $21,0 \%$ & & $20,7 \%$ & & $20,7 \%$ & \\
\hline Raramente & $12,9 \%$ & \multirow{2}{*}{$15,4 \%$} & $25,7 \%$ & \multirow{2}{*}{$40,1 \%$} & $29,0 \%$ & \multirow{2}{*}{$68,2 \%$} & $25,7 \%$ & \multirow{2}{*}{$58,3 \%$} & $21,0 \%$ & \multirow{2}{*}{$39,3 \%$} \\
\hline Nunca & $2,5 \%$ & & $14,4 \%$ & & $39,2 \%$ & & $32,6 \%$ & & $18,3 \%$ & \\
\hline
\end{tabular}




\begin{tabular}{|c|c|c|c|c|c|c|c|}
\hline \multirow{2}{*}{\multicolumn{2}{|c|}{$\begin{array}{l}\text { Comportamentos dos alunos } \\
\text { da UM face ao tabaco }\end{array}$}} & \multicolumn{5}{|c|}{ Frequência de consumo de tabaco } & \multirow{3}{*}{$\begin{array}{c}p^{*} \\
<0,0001\end{array}$} \\
\hline & & \multirow{2}{*}{$\begin{array}{c}\text { Pelo menos } \\
1 \text { vez/dia } \\
6,1 \%\end{array}$} & \multirow{2}{*}{ 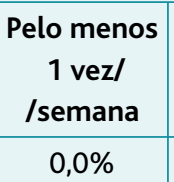 } & \multirow{2}{*}{$\begin{array}{c}\text { Pelo menos } \\
1 \text { vez/mês } \\
0,0 \%\end{array}$} & \multirow{2}{*}{\begin{tabular}{|c|}
$\begin{array}{c}\text { Pelo menos } \\
1 \text { vez/ano }\end{array}$ \\
$4,8 \%$ \\
\end{tabular}} & \multirow{2}{*}{$\begin{array}{c}\text { Menos de } \\
1 \text { vez/ano } \\
36,3 \%\end{array}$} & \\
\hline Frequência com que se & Sempre & & & & & & \\
\hline sentem incomodados & Frequentemente & $2,0 \%$ & $18,2 \%$ & $0,0 \%$ & $28,6 \%$ & $29,2 \%$ & \\
\hline pela exposição ao fumo & Às vezes & $44,9 \%$ & $27,3 \%$ & $66,7 \%$ & $42,9 \%$ & $29,2 \%$ & \\
\hline de tabaco & Raramente & $36,7 \%$ & $45,5 \%$ & $16,7 \%$ & $23,8 \%$ & $5,3 \%$ & \\
\hline & Nunca & $10,2 \%$ & $9,1 \%$ & $16,7 \%$ & $0,0 \%$ & $0,0 \%$ & \\
\hline Frequência com que & Sempre & $0,0 \%$ & $0,0 \%$ & $0,0 \%$ & $0,0 \%$ & $7,1 \%$ & $<0,0001$ \\
\hline abandonam um local & Frequentemente & $0,0 \%$ & $9,1 \%$ & $8,3 \%$ & $14,3 \%$ & $25,7 \%$ & \\
\hline onde é permitido fumar & Às vezes & $18,4 \%$ & $18,2 \%$ & $33,3 \%$ & $28,6 \%$ & $29,2 \%$ & \\
\hline & Raramente & $40,8 \%$ & $54,5 \%$ & $25,0 \%$ & $38,1 \%$ & $27,4 \%$ & \\
\hline & Nunca & $40,8 \%$ & $18,2 \%$ & $33,3 \%$ & $19,0 \%$ & $10,6 \%$ & \\
\hline
\end{tabular}

* valor de p obtido pelo teste do Qui-Quadrado.

\begin{tabular}{|c|c|c|c|}
\hline $\begin{array}{l}\text { QUADRO V. Frequência com qu } \\
\text { fumador para não fumar num } \\
\text { consumo de tabaco em função }\end{array}$ & $\begin{array}{l}\text { alunos da UI } \\
\text { nde não é p } \\
\text { nero. }\end{array}$ & $\begin{array}{l}\text { pedem a } ~ \\
\text { ermitido o }\end{array}$ & \\
\hline \multirow{2}{*}{$\begin{array}{l}\text { Frequência com que pede a um } \\
\text { fumador para não fumar num } \\
\text { local onde não é permitido }\end{array}$} & \multicolumn{2}{|c|}{ Género } & \multirow[b]{2}{*}{$p^{*}$} \\
\hline & Masculino & Feminino & \\
\hline Sempre & $28,6 \%$ & $20,5 \%$ & \multirow{5}{*}{0,046} \\
\hline Frequentemente & $13,3 \%$ & $18,8 \%$ & \\
\hline Às vezes & $18,1 \%$ & $21,8 \%$ & \\
\hline Raramente & $15,2 \%$ & $23,6 \%$ & \\
\hline Nunca & $24,8 \%$ & $15,3 \%$ & \\
\hline
\end{tabular}

*valor de p obtido pelo teste do Qui-Quadrado.

\section{Conhecimentos}

\subsection{Conhecimentos acerca do tabaco}

A grande maioria dos respondentes $(72,8 \%)$ considerava que a probabilidade de o consumo de tabaco causar problemas de saúde é elevada. No entanto, os restantes $27,2 \%$ não atribuíram tanta importância aos efeitos do tabaco na saúde e, apesar de este valor ser semelhante à prevalência de fumadores encontrada nes- te estudo (27,9\%), não houve diferenças estatisticamente significativas $(p=0,654)$ entre fumadores e não fumadores, relativamente a esta questão (quadro VI).

Quando se questionou sobre a quantidade e duração de consumo de tabaco que são prejudiciais para a saúde, a maioria dos respondentes $(81,4 \%$ e $90,1 \%$, respectivamente) (quadro VII) respondeu que todo o nível de consumo tem efeitos deletérios.

Comparando as respostas a estas questões entre fumadores e não fumadores, verificou-se que os fumadores regulares e os fumadores ocasionais que consomem tabaco mais do que uma vez por semana ou por mês eram aqueles que mais consideravam que o tabaco tem um limiar de exposição seguro no que toca à quantidade de tabaco consumida ( $p=0,018$ - quadro VIII). Relativamente à duração do consumo não houve diferenças estatisticamente significativas ( $p=0,402$ - quadro VIII).

Quase todos os respondentes tinham a percepção de que o consumo de tabaco causa dependência $(99,4 \%)$ e que tem efeitos nocivos para o feto quando a grávida é fumadora $(99,4 \%)$. 


\begin{tabular}{|c|c|c|c|c|c|c|}
\hline \multicolumn{7}{|c|}{$\begin{array}{l}\text { QUADRO VI. Opinião dos alunos da UM sobre a probabilidade do consumo de tabaco prejudicar a } \\
\text { saúde em função da frequência de consumo de tabaco. }\end{array}$} \\
\hline \multirow{2}{*}{$\begin{array}{l}\text { Probabilidade do } \\
\text { consumo de tabaco } \\
\text { prejudicar a saúde } \\
\text { do fumador }\end{array}$} & \multicolumn{6}{|c|}{ Frequência de consumo de tabaco } \\
\hline & $\begin{array}{l}\text { Pelo menos } \\
1 \mathrm{vez} / \mathrm{dia}\end{array}$ & $\begin{array}{c}\text { Pelo menos } \\
1 \text { vez/semana }\end{array}$ & $\begin{array}{c}\text { Pelo menos } \\
1 \text { vez/mês }\end{array}$ & $\begin{array}{l}\text { Pelo menos } \\
1 \text { vez/ano }\end{array}$ & $\begin{array}{l}\text { Menos de } \\
1 \text { vez/ano }\end{array}$ & $p^{*}$ \\
\hline Elevada & $71,4 \%$ & $72,7 \%$ & $75,0 \%$ & $76,2 \%$ & $64,6 \%$ & \multirow{4}{*}{0,654} \\
\hline Intermédia & $24,5 \%$ & $27,3 \%$ & $16,7 \%$ & $23,8 \%$ & $26,5 \%$ & \\
\hline Baixa & $4,1 \%$ & $0,0 \%$ & $0,0 \%$ & $0,0 \%$ & $7,1 \%$ & \\
\hline Nula & $0,0 \%$ & $0,0 \%$ & $8,3 \%$ & $0,0 \%$ & $1,8 \%$ & \\
\hline
\end{tabular}

* valor de p obtido pelo teste do Qui-Quadrado.

\begin{tabular}{|c|c|c|}
\hline \multicolumn{3}{|c|}{$\begin{array}{l}\text { QUADRO VII. Opinião dos alunos da UM sobre a quantidade de } \\
\text { cigarros consumidos por dia e a duração do consumo que } \\
\text { prejudicam a saúde do fumador. }\end{array}$} \\
\hline & & Frequência (\%) \\
\hline \multirow{7}{*}{$\begin{array}{l}\text { N. }{ }^{\circ} \text { de cigarros } \\
\text { consumidos por dia } \\
\text { necessários para } \\
\text { prejudicar a saúde } \\
\text { do fumador }\end{array}$} & 1 a 5 & 4,2 \\
\hline & 6 a 10 & 5,4 \\
\hline & 11 a 15 & 4,2 \\
\hline & 16 a 20 & 1,8 \\
\hline & Mais de 20 & 2,4 \\
\hline & Todas as anteriores & 81,4 \\
\hline & Nenhuma das anteriores & 0,6 \\
\hline \multirow{6}{*}{$\begin{array}{l}\text { N. }{ }^{\circ} \text { de anos de } \\
\text { consumo de tabaco } \\
\text { necessários para } \\
\text { prejudicar a saúde } \\
\text { do fumador }\end{array}$} & 1 a 10 & 4,5 \\
\hline & 11 a 20 & 2,4 \\
\hline & 21 a 30 & 1,8 \\
\hline & Mais de 40 & 0,6 \\
\hline & Todas as anteriores & 90,1 \\
\hline & Nenhuma das anteriores & 0,6 \\
\hline
\end{tabular}

bons ( $11,7 \%$ «excelente» e $48,8 \%$ «bom»), sendo os indivíduos do género masculino aqueles que mais avaliaram os seus conhecimentos como «excelentes» (20\%, comparativamente com $7,9 \%$ do género oposto).

\subsection{Conhecimentos acerca da Lei $n^{\circ}$ 37/2007, de 14 de Agosto}

A quase totalidade dos respondentes $(98,5 \%)$ sabia da existência, em Portugal, de legislação que proíbe o consumo de tabaco em determinados locais.

Na questão «Em quais dos locais abaixo mencionados é permitido fumar, por lei, em Portugal?» foi registada uma grande variedade de respostas, pois era permitido escolher mais do que uma opção. Assim, de entre as 51 respostas diferentes obtidas, as opções «espaços ao ar livre», «estabelecimentos de restauração e bebidas» e «recintos de diversão» foram das mais assinaladas, isoladamente ou em combi-

De igual modo, a quase totalidade dos respondentes considerou que o fumo do tabaco ambiental «causa desconforto e problemas de saúde» para o não fumador $(95,2 \%)$ e apenas uma minoria $(0.9 \%)$ disse que «é inofensivo". Relativamente à contribuição do fumo do tabaco para a contaminação do ar de espaços fechados, a maioria dos respondentes classificou-a como «elevada» (90.1\%).

Finalmente, $60,5 \%$ dos respondentes considerou que os seus conhecimentos sobre o tabaco são pelo menos nação $(92,8 \%, 21,6 \%$ e 17,4\%, respectivamente). É de destacar que $58,1 \%$ dos respondentes assinalou apenas a opção espaços ao ar livre, o que se encontra de acordo com a lei, segundo a qual é proibido fumar em espaços públicos fechados, tal como todos os espaços fechados referidos no enunciado da questão. Alguns alunos consideraram que é permitido fumar em «estabelecimentos de ensino e outros locais destinados a menores de 18 anos» $(0,6 \%)$, "parques de estacionamento cobertos» $(6,9 \%)$, «bibliotecas» $(0,3 \%)$ e «espa- 


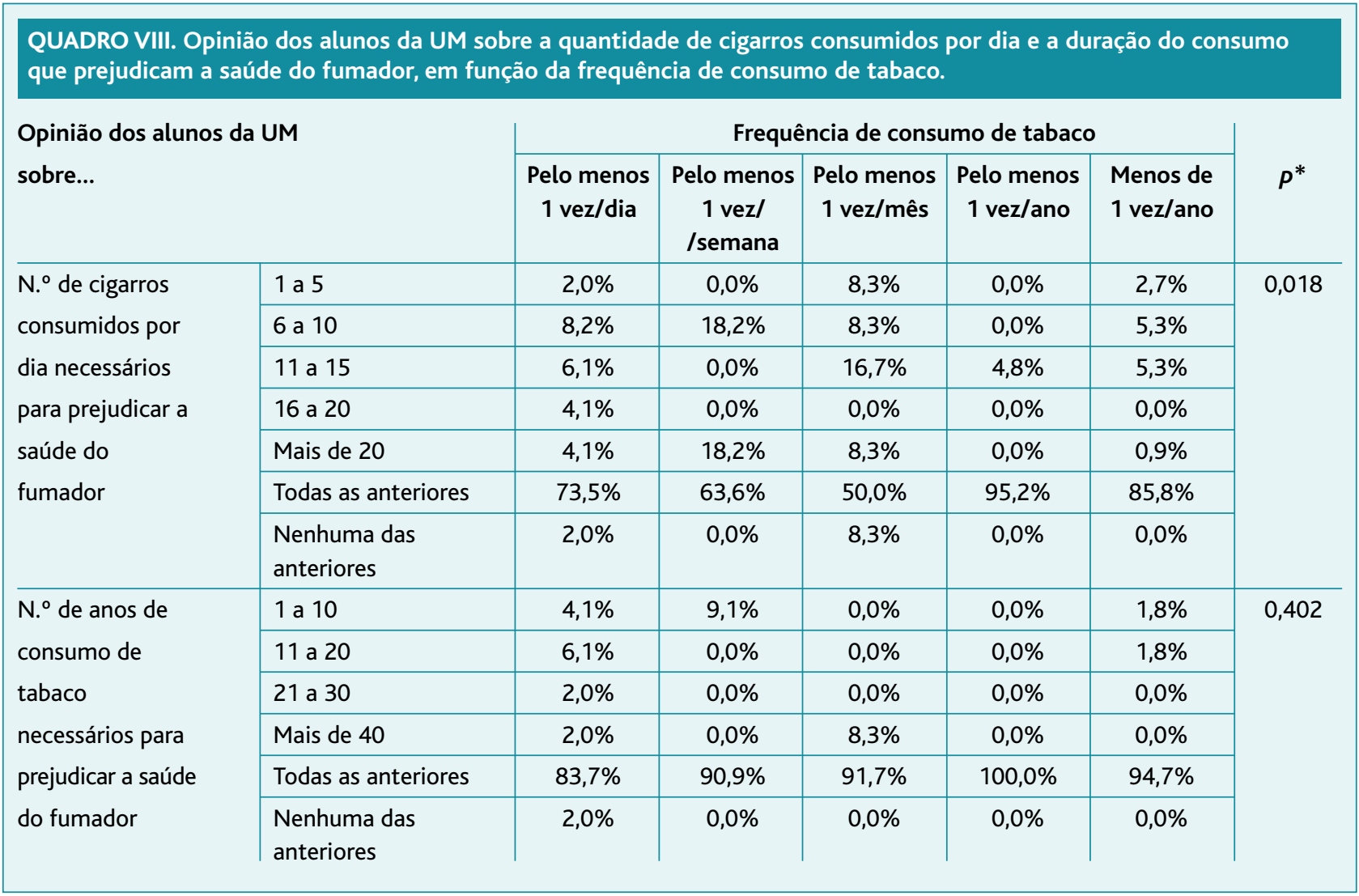

*valor de p obtido pelo teste do Qui-Quadrado.

ços de atendimento público» $(0,6 \%)$, quando para estes locais a lei não abre qualquer excepção e é explícita quanto à proibição de fumar.

Ao questionar os alunos sobre os locais onde é permitido fumar por lei na UM, 92,5\% assinalaram a opção «espaços ao ar livre»; contudo, destes, $45,2 \%$ responderam correctamente, ao assinalar apenas esta opção, pois os restantes assinalaram também outras opções. Das 20 respostas diferentes obtidas, a opção «áreas fechadas expressamente previstas para o efeito" foi a segunda mais assinalada (32,9\%). Além disto, alguns alunos consideraram ser permitido fumar nos átrios, corredores, salas de professores, bares e refeitórios da UM, quando a lei é explícita ao definir, na alínea g) do artigo $4 .^{\circ}$, que nestes locais dos estabelecimentos de ensino é proibido o consumo de tabaco (Lei n.o 37/2007). Ao comparar por área de curso, verifica-se que os alunos que frequentam «outros cursos» foram aqueles que mais assinalaram a resposta correcta - «espaços ao ar livre» -
(49\%), ao contrário dos alunos do "curso de psicologia» que a assinalaram em menor frequência $(28,6 \%)$.

\section{Opinião sobre a Lei $n .{ }^{\circ} 37 / 2007$, de 14 de Agosto e o seu impacto}

A grande maioria dos alunos (96,1\%) concordou com a proibição do consumo de tabaco nos espaços fechados da UM. A opinião dos respondentes relativamente a esta questão parece estar associada a ser fumador $(p<0,0001)$. Na verdade, apenas entre os fumadores regulares e os fumadores que consomem tabaco pelo menos uma vez por mês ou por ano houve quem discordasse desta medida (quadro IX).

Relativamente à opinião dos alunos acerca do impacto da lei no padrão de consumo dos fumadores, a maioria dos indivíduos $(79,6 \%)$ acreditava que esta iria ter como consequência uma redução do número de cigarros consumidos por dia. No entanto, $16,2 \%$ dos respondentes consideraram que as medidas implementa- 
das não irão produzir qualquer alteração.

Do total de respondentes, $91,3 \%$ admitiram que com a lei o ambiente dos espaços fechados da UM «melhorou muito» $(53,9 \%)$ ou «melhorou» $(37,4 \%)$ e apenas $6,0 \%$ consideraram que «manteve-se igual». Contudo, existiram diferenças estatisticamente significativas entre fumadores e não fumadores ( $p=0,001)$, uma vez que $20,4 \%$ dos fumadores regulares considerou que o ambiente «manteve-se igual», quando apenas $3,5 \%$ dos não fumadores actuais assinalou esta opção (quadro X).
5. Impacto percebido da Lei n. ${ }^{\circ}$ 37/2007 de 14 de Agosto

Com a implementação da proibição do consumo de tabaco nos espaços fechados da UM, a maioria dos respondentes $(59,1 \%)$ revelou fumar apenas ao ar livre, sendo que $37,6 \%$ deixaram inclusive de fumar na universidade. No entanto, $3,3 \%$ dos alunos admitiram continuar a fumar em locais públicos fechados.

Ao avaliar os padrões de consumo dos fumadores, após a instituição da lei, 45,2\% afirmaram ter diminuído o consumo de tabaco e $24,7 \%$ revelaram ter cessa-

\begin{tabular}{|c|c|c|c|c|c|c|}
\hline \multirow{2}{*}{$\begin{array}{l}\text { Opinião sobre a proibição } \\
\text { do consumo de tabaco nos } \\
\text { espaços fechados da UM }\end{array}$} & \multicolumn{5}{|c|}{ Frequência de consumo de tabaco } & \multirow[b]{2}{*}{$p^{*}$} \\
\hline & $\begin{array}{c}\text { Pelo menos } \\
1 \text { vez dia }\end{array}$ & $\begin{array}{c}\text { Pelo menos } \\
1 \text { vez/ } \\
\text { /semana }\end{array}$ & $\begin{array}{l}\text { Pelo menos } \\
1 \text { vez/mês }\end{array}$ & $\begin{array}{c}\text { Pelo menos } \\
1 \text { vez/ano }\end{array}$ & $\begin{array}{l}\text { Menos de } \\
1 \text { vez/ano }\end{array}$ & \\
\hline Concorda completamente & $51,0 \%$ & $90,9 \%$ & $58,3 \%$ & $85,7 \%$ & $88,5 \%$ & \multirow[t]{4}{*}{$<0,0001$} \\
\hline Concorda & $32,7 \%$ & $9,1 \%$ & $16,7 \%$ & $9,5 \%$ & $10,6 \%$ & \\
\hline Discorda & $16,3 \%$ & $0,0 \%$ & $8,3 \%$ & $0,0 \%$ & $0,9 \%$ & \\
\hline Discorda completamente & $0,0 \%$ & $0,0 \%$ & $16,7 \%$ & $4,8 \%$ & $0,0 \%$ & \\
\hline
\end{tabular}

* valor de p obtido pelo teste do Qui-Quadrado.

\section{QUADRO X. Opinião dos alunos sobre a alteração do ambiente dos espaços fechados da UM com a proibição de fumar nestes locais, em função da frequência de consumo de tabaco.}

Opinião sobre o impacto no ambiente dos espaços fechados da UM com a proibição do consumo de tabaco

*valor de p obtido pelo teste do Qui-Quadrado. 
do; ainda assim, $29 \%$ dos alunos mantiveram o consumo e $1,1 \%$ aumentaram-no.

\section{DISCUSSÃO}

Sabendo que o tabaco é a principal causa isolada e evitável de doença e morte no mundo ocidental, e que o fumo causado pelo seu consumo constitui o principal poluente evitável do ar interior, julgou-se importante desenvolver um trabalho de investigação nesta área. Para tal, e face a uma nova legislação do tabaco em Portugal, considerou-se oportuno desenvolver um estudo que, na fase de implementação desta lei, procurasse perceber conhecimentos e opiniões junto de uma população jovem, maioritariamente saudável, onde a promoção de hábitos e estilos de vida saudáveis assumem um papel importante.

Iniciando esta discussão dos resultados pelo padrão de consumo dos inquiridos, verificou-se que $38,0 \%$ nunca experimentaram fumar. A prevalência de fumadores encontrada foi, contudo, ligeiramente superior à apresentada num estudo efectuado na UM em 2002, que apontava para $24 \%$. Tal deveu-se provavelmente a um aumento dos fumadores ocasionais (que passaram de $6 \%$ no referido estudo para $13,2 \%$ no presente) uma vez que a percentagem de fumadores regulares até diminuiu (passando de $18 \%$ no referido estudo para $14,7 \%$ no presente) ${ }^{13}$ Assim, embora fumar continue a ser um hábito predominantemente regular, à semelhança do que é apontado no Eurobarómetro 2007, segundo o qual $89 \%$ dos fumadores portugueses consumiam tabaco «pelo menos uma vez/dia», é possível que, com a implementação da Lei n. ${ }^{\circ} 37 / 2007$, se vá assistir a uma mudança nos padrões de consumo: uma fracção significativa dos indivíduos que fumavam regularmente poderá começar a fazê-lo apenas de forma ocasional. ${ }^{6}$ A frequência de consumo de tabaco pareceu ainda variar com o sexo, uma vez que o consumo regular esteve mais presente nos indivíduos do sexo masculino, enquanto que o consumo esporádico se encontrou preferencialmente no sexo feminino. Embora numa população mais restrita, estes dados estão de acordo com o encontrado no Eurobarómetro 2006, segundo o qual $43 \%$ dos homens fumavam regularmente contra apenas $14 \%$ das mulheres. ${ }^{5}$ Tal também ficou evidente noutros estudos, nomeadamente num efectuado na UM em 2002, segundo o qual $8 \%$ das raparigas e apenas $4 \%$ dos rapazes fumavam ocasionalmente. ${ }^{13}$

Apenas 5,8\% dos indivíduos tiveram a primeira experiência de consumo de tabaco na universidade, resultados que diferem significativamente dos apresentados pelo estudo efectuado na UM em 2002, em que o valor foi de $29 \%$; nesse estudo concluiu-se ainda que $22 \%$ dos alunos começaram a fumar antes dos 15 anos e $49 \%$ dos 15 aos 18 anos. Em conjunto os dados dos dois estudos podem sugerir que a entrada na universidade não é o principal factor indutor do início do consumo e que os jovens começam a fumar cada vez mais cedo. ${ }^{13}$ De facto, já no Eurobarómetro 2006, 80\% dos novos fumadores apresentavam menos de 18 anos de idade. ${ }^{5}$

Quanto ao número de cigarros consumidos diariamente, os resultados aqui encontrados contrastam com os do Eurobarómetro 2007, segundo o qual os portugueses eram dos indivíduos que mais fumavam na UE: apenas $27 \%$ consumia até 10 cigarros/dia (versus $51,6 \%$ neste estudo) enquanto que $38 \%$ consumia mais de 20 cigarros/dia (versus $13 \%$ ). ${ }^{7}$ Nesta diferença entre o cenário traçado em 2007 e aquele aqui encontrado em 2008, levantamos a hipótese da implementação da Lei n. ${ }^{\circ} 37 / 2007$ poder estar associada a uma redução no consumo diário de cigarros; contudo, estas conclusões devem ser tomadas com os devidos cuidados e não esquecendo que estes estudos abrangem populações de faixas etárias e condicionantes diferentes.

A percentagem de indivíduos que referiu fumar em casa $(49,5 \%)$ foi significativamente inferior ao referido no Eurobarómetro 2006, onde $73 \%$ dos portugueses afirmavam fazê-lo, sendo a média comunitária de $80 \%{ }^{5}$ Tal poderá apontar para uma tomada de consciência por parte dos estudantes dos malefícios da exposição involuntária. Não se pode, todavia, excluir que outras circunstâncias estejam associadas a este aspecto, tais como o facto de muitos jovens não fumarem em casa por não se sentirem a vontade em fazê-lo a frente dos pais. Por outro lado, dados mais recentes do Eurobarómetro 2007 já revelavam que $49 \%$ dos europeus começaram a aplicar medidas de restrição ao fumo de tabaco nos seus domicílios, reduzindo-se de $63 \%$ para $11 \%$ e $6 \%$ a percentagem de indivíduos que nunca se abstém de fumar em casa quando nela existem crianças e grávidas, respectivamente. ${ }^{6} \mathrm{O}$ quase unânime reconhecimento do direito dos não fumadores respirarem 
ar livre de tabaco revelado neste estudo ficou ainda bem expresso no facto de a maioria dos fumadores afirmar abster-se de fumar na presença de indivíduos não fumadores pelo menos às vezes, tal como vem sendo referido noutros estudos, por exemplo no Eurobarómetro 2007 , onde $35 \%$ dos europeus referiam fumar apenas ocasionalmente na presença de fumadores involuntários e $34 \%$ referem nunca o fazer. ${ }^{6}$ Estes dados vêm reforçar a ideia de que a regulamentação do consumo parece resultar numa mudança comportamental do fumador face aos outros. Depois do domicílio, os locais mais frequentes de consumo assinalados pelos inquiridos reflectem os hábitos e estilos de vida dos estudantes universitários, sobretudo consumidores ocasionais e sociais, predominantemente em bares, discotecas e outros estabelecimentos de restauração e bebidas.

Apenas 36,5\% dos inquiridos nunca tentaram deixar de fumar, enquanto a maioria já o fez, dados ligeiramente diferentes dos encontrados no Eurobarómetro 2007 , em que $32 \%$ dos portugueses afirmavam ter tentado deixar de fumar no último ano mas $67 \%$ referiam nunca ter tentado deixar de fumar. ${ }^{11}$ Isto pode estar associado, por um lado, ao facto da lei ter sido implementada após a realização do estudo atrás referido, o que se traduziu num aumento da percentagem de tentativas de cessação do consumo tabágico; e, por outro, ao facto da população em estudo ser constituída neste caso por jovens, que está documentado serem aqueles que mais facilmente tentam e conseguem deixar de fumar. ${ }^{6}$ A grande maioria dos inquiridos $(84,6 \%)$ afirmou sentir-se incomodada com o fumo de tabaco, o que contrasta significativamente com os dados do Eurobarómetro $2006 \mathrm{em}$ que apenas $42 \%$ dos portugueses o referiam. ${ }^{5}$ Este facto apresenta-se como um motivo suficientemente forte para levar a maioria a abandonar os locais onde é permitido fumar; no entanto, o número de inquiridos a tomar a iniciativa de pedir ao fumador para não fumar, ou para não o fazer perto de si, era de apenas de $31,8 \%$, provavelmente porque se sentiam constrangidos em pedir a alguém para mudar um comportamento que não constitui uma infracção à lei. Este valor subiu quando a questão em causa se referia a locais onde não é permitido fumar; aqui, $60,7 \%$ dos inquiridos afirmaram pedir a fumadores para não fumarem, ou para não o fazerem perto de si. Este dado parece indi- car que a implementação de medidas de regulamentação do consumo tem permitido que as pessoas se sintam mais seguras para defender os seus direitos. $\mathrm{Na}$ verdade, é compreensível que as pessoas se sintam mais à vontade para pedir a um fumador para não fumar num local onde não é permitido do que num local onde é, sobretudo se tivermos em conta que actualmente os não fumadores podem escolher locais livres de fumo de tabaco. Embora não tenha sido feita a distinção entre locais onde é ou não permitido fumar no Eurobarómetro 2006 , o estudo revela que $52 \%$ dos portugueses pediam pelo menos às vezes a um fumador para não fumar perto de si quando incomodados, dados que vêm ao encontro dos apresentados no presente estudo. ${ }^{5}$

O nível de conhecimentos dos alunos da UM relativamente ao impacto do tabaco na saúde foi, globalmente, bom, pois em todas as questões formuladas para avaliar este aspecto a grande maioria dos alunos assinalou a resposta considerada correcta, o que estava de acordo com a auto-avaliação que os indivíduos fizeram dos seus conhecimentos em relação aos efeitos, benefícios, consequências e outras características do tabaco (a maioria considerou que são pelo menos bons). Apenas uma minoria dos alunos considerou que o fumo do tabaco «é inofensivo», o que está de acordo com os dados encontrados pelo Eurobarómetro 2007, em que $1 \%$ dos portugueses considerava que fumar junto de não fumadores não tem riscos. ${ }^{6}$ Apesar de a maioria dos inquiridos considerar que a probabilidade do consumo de tabaco causar problemas de saúde é elevada, os fumadores foram aqueles que menos valorizaram os efeitos deletérios do tabaco na saúde. Além disso, foram também os fumadores os que mais consideraram que o tabaco tem um limiar de exposição seguro no que toca à quantidade consumida. Sendo assim, talvez se possa inferir que, apesar de globalmente os indivíduos possuírem os conhecimentos, muitas vezes um hábito adquirido assume-se como uma dependência de tal forma forte que os leva a consumir, negligenciando os prejuízos na saúde.

Apesar da quase totalidade dos inquiridos ter demonstrado que sabe da existência em Portugal de legislação que proíbe o consumo de tabaco em determinados locais, os conhecimentos sobre a nova lei do tabaco estavam, ainda, bastante aquém dos ideais, sobretudo no se que refere aos locais específicos onde é 
permitido ou proibido fumar. Os resultados obtidos devem, contudo, ser analisados com cuidado e ter em consideração dois pontos fundamentais: primeiro, o facto de a lei obedecer a um princípio geral, segundo a qual é proibido fumar em espaços públicos fechados, mas contemplar, também, algumas excepções, o que pode ter contribuído para a dispersão de respostas; segundo, as opções apresentadas no questionário, cruzando estes aspectos de forma implícita, podem ter induzido a alguma dificuldade de interpretação nos inquiridos. A maioria dos alunos afirmou concordar com a proibição de fumar nos locais fechados da UM, valor que é superior ao apresentado no Eurobarómetro 2006 (83\%). ${ }^{5}$ Este dado permite concluir que os estudantes da UM têm uma opinião positiva quanto à nova lei do tabaco actualmente em vigor em Portugal e, particularmente, no seu local de estudo. Os resultados obtidos neste estudo sugerem também que as medidas legislativas estão a surtir o efeito desejado, reduzindo a contaminação do ar interior, a exposição involuntária e, assim, os efeitos nefastos do tabaco na saúde. De facto, além de concordarem com a proibição de fumar nos locais fechados da UM, a maioria dos alunos afirmou não fumar em locais públicos fechados, passando a fazê-lo apenas ao ar livre, e mais de um terço afirmou ter deixado de fumar na universidade o que, a ser verdade na prática, poderá ter resultado na melhoria da qualidade do ar interior. Ainda assim, alguns alunos $(3,3 \%)$ admitiram continuar a fumar em locais públicos fechados, o que denota ainda algum incumprimento da lei ou mesmo que a verificação da aplicação desta não está a ser suficientemente controlada.

Sabendo que fumar constitui um grave problema de saúde pública, e apesar das limitações deste estudo, parece positiva a possibilidade da Lei n. ${ }^{\circ}$ 37/2007, de 14 de Agosto, poder contribuir não só para a protecção do não fumador da exposição involuntária ao fumo ambiental, como também para a diminuição do número de fumadores. Na verdade, após a implementação da lei, quase metade dos fumadores afirmou ter diminuído o consumo de tabaco e um quarto cessou mesmo o consumo. No entanto, parecem ser ainda necessárias outras estratégias que apoiem os restantes alunos que mantiveram o consumo ou o aumentaram a deixar de fumar.

Apesar de todo o esforço realizado na condução do estudo para que a informação recolhida representasse o mais possível os conhecimentos e comportamentos dos alunos da UM face ao tabaco, a concretização deste objectivo pode ter sido dificultada por certas limitações inerentes a qualquer estudo de investigação. Desde logo, o próprio processo de amostragem utilizado, não tendo sido aleatório (por razões anteriormente já explicitadas), limita a extrapolação dos resultados para toda a população em estudo. No entanto, pode-se considerar que este viés foi minimizado pelos cuidados tomados na técnica de amostragem de conveniência. Assim, o facto de a população ter sido dividida em quatro estratos permitiu garantir a representatividade em termos de cursos incluídos na amostra. Relativamente a outras características sócio-demográficas, os dados fornecidos pelos Serviços Académicos da UM apenas continham a informação relativa ao sexo dos alunos inscritos, não tendo sido muito díspar a diferença entre a amostra (sexo feminino: $68,6 \%$; sexo masculino: $31,4 \%$ ) e a população (sexo feminino: $58,0 \%$; sexo masculino: $42,0 \%)$.

Não obstante a existência de alguns viéses, como o referido anteriormente, e outros inerentes ao tipo de informação recolhida, ao questionário em si e à forma como os estudantes responderam (respostas politicamente correctas, por exemplo), consideramos ter alcançado os objectivos propostos.

Em síntese, os estudantes da UM parecem estar bem informados acerca dos malefícios do tabaco. Mais de metade dos inquiridos já havia experimentado tabaco, mas apenas $27,9 \%$ se declaram fumadores regulares. $\mathrm{O}$ nível de conhecimento da Lei também foi bom, e a grande maioria concordava com a proibição do consumo de tabaco nos espaços fechados da UM, passando a fumar apenas ao ar livre. Uma percentagem significativa dos estudantes $(45,2 \%)$ afirmou ter diminuído o seu consumo e $24,7 \%$ ter deixado de fumar. Além destas conclusões, que nos parecem positivas face à implementação da Lei n. ${ }^{\circ}$ 37/2007, de 14 de Agosto, esperamos que este trabalho possa contribuir para futuros estudos que preencham eventuais lacunas e acrescentem novos dados como, por exemplo, conhecer comportamentos e opiniões face ao tabaco e à lei de outros elementos da UM (professores, funcionários), perceber os estímulos para que os jovens comecem a fumar e os que dificultam os fumadores a cessar o consumo 
e, ainda, estudos que possam testar algumas das hipóteses aqui levantadas.

\section{REFERÊNCIAS BIBLIOGRÁFICAS}

1. International Union Against Cancer Newsletter. 2002 Aug 13; 13 (1).

2. Eriksen M, Mackay J. The Tobacco Atlas. Geneva:World Health Organization; 2002.

3. Peto R, Lopez AD, Boreham J, Thun M. Mortality from smoking in developed countries 1950-2000. 2nd ed. New York: Oxford University Press; 2006.

4. World Health Organization. European Country Profiles on Tobacco Control. Copenhagen:WHO Regional Office for Europe; 2001.

5. Special Eurobarometer 239. Attitudes of Europeans towards Tobacco. EU: TNS Opinion \& Social; 2006.

6. Special Eurobarometer 239. Attitudes of Europeans towards Tobacco. EU:TNS Opinion \& Social; 2007.

7. Nunes E. Consumo de tabaco: Estratégias de Prevenção e Controlo. Lisboa: Direcção-Geral de Saúde; 2002.

8. DEPS. Inquérito Nacional de Saúde - 1995//1996 Continente. Lisboa: Ministério da Saúde; 1997.

9. Commission of the European Communities. Green Paper:Towards a Europe free from tobacco smoke. Brussels: European Union; 2007.

10. Wechsler H, Lee JE, Rigotti NA. Cigarette use by college students in smoke-free housing: results of a national study. Am J Prev Med 2001
Apr; 20 (3): 202-7.

11. Decreto-Lei n. ${ }^{\circ}$ 37/2007, de 14 de Agosto. «Diário da República» n. ${ }^{\circ}$

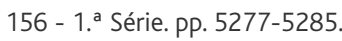

12. World Health Organization. WHO Framework Convention on Tobacco Control. Geneva: World Health Organization; 2005.

13. Precioso J. Quando e porquê começam os estudantes universitários a fumar: implicações para a prevenção. Análise Psicológica 2004; 3 (22): 499-506.

14. Borders TF, Xu KT, Bacchi D, Cohen L, SoRelle-Miner D. College campus smoking policies programs and students' smoking behaviours. BMC Public Health 2005 Jul 7; 5: 74.

\section{CONFLITOS DE INTERESSE}

As autoras declaram não existirem conflitos de interesse na elaboração deste artigo.

\section{ENDEREÇO PARA CORRESPONDÊNCIA}

Viviana Manuel Magno de Azevedo

Av. Carlos Alberto Teixeira Azevedo, 135

4475-327 MAIA

E-mail: viviana_azevedo@hotmail.com

Recebido em 23/03/2009

Aceite para publicação em 04/07/2010

\section{ABSTRACT}

\section{MINHO UNIVERSITY TOBACCO - FREE: A NEW REALITY}

Objectives: to characterize the pattern of consumption of Minho University (UM) students; to determine their knowledge and behaviour in relation to tobacco and Law nr. 37/2007; to know their opinion about the application of this law at UM and its impact on tobacco consumption and indoor air quality.

Type of study: cross-sectional.

Location: UM; Gualtar - Braga campus

Population: Students enrolled in undergraduate or master's integrated programmes of UM, in the academic year of 2007/2008. Methods: A questionnaire was administered to a convenience sample of 334 individuals of the total 9028 students enrolled. A $\chi$-square test and a significance level of 0.05 were used.

Results: $62 \%$ of students surveyed have tried tobacco, $5.8 \%$ of which did it college. In the sample $27.9 \%$ of students were smokers, and of these, $51.6 \%$ consumed between one and 10 cigarettes per day and $13 \%$ smoked more than 20 cigarettes per day. The majority stated not to smoke in enclosed public spaces and in the UM they only smoke in outdoors. Students showed a good level of knowledge regarding the impact of tobacco on health, which was lower in smokers and in those who have tried to consume. Most of the respondents knew of the existence of legislation prohibiting smoking in certain places, $96.1 \%$ agreed with the prohibition of the consumption in the enclosed spaces of $U M$ and this opinion depended on being a smoker, because it was among those that some disagreed with the measure. In the opinion of $91.3 \%$ of respondents, the environment of indoor UM improved with the smoking ban. With this law, most students started to smoke only outdoors, $45.2 \%$ decreased their consumption and $24.7 \%$ stopped smoking.

Conclusions: The Tobacco's Law seems to be contributing to reduce the number of smokers and to the protection of non-smokers from environmental tobacco.

Keywords: Smoking; Legislation; Students; University. 


\section{ANEXO I}

Este inquérito foi elaborado no âmbito da área curricular «Residências em Centros de Saúde», que integra o plano curricular do Mestrado Integrado em Medicina da Universidade do Minho. Destina-se à realização de um projecto de investigação. $O$ anonimato de todos os participantes está garantido.

Autoras: Adelaide Abreu, Ana Marques, Isabel Silva e Viviana Azevedo

\section{QUESTIONÁRIO}

$\begin{array}{ll}\text { Data de nascimento: } & \text { Sexo: } \mathrm{F} \quad \mathrm{M} \\ \text { Curso: } & \text { Ano de curso:_____ }\end{array}$

Por favor, assinale com um X ( ) a resposta que considere correcta. Todas as questões são de resposta única, excepto quando se indica o contrário (questões 8, 9, 28 e 29).

\section{Grupo 1:}

1. Com que frequência se sente incomodado pela exposição ao fumo do tabaco?

Sempre

Frequentemente

Às vezes

Raramente

Nunca

2. Quando se sente incomodado pelo fumo do cigarro de outra pessoa, num local onde é permitido o consumo de tabaco, com que frequência abandona o local?

Sempre

Frequentemente

Às vezes

Raramente

Nunca

3. Quando se sente incomodado pelo fumo do cigarro de outra pessoa, num local onde é permitido o consumo de tabaco, com que frequência pede ao fumador para não fumar ou para não o fazer perto de si?

\section{Sempre}

Frequentemente

Às vezes

Raramente

Nunca

4. Quando se sente incomodado pelo fumo do cigarro de outra pessoa, num local onde não é permitido o consumo de tabaco, com que frequência abandona o local?

Sempre

Frequentemente

Às vezes

Raramente

Nunca

5. Quando se sente incomodado pelo fumo do cigarro de outra pessoa, num local onde não é permitido o consumo de tabaco, com que frequência pede ao fumador para não fumar ou para não o fazer perto de si?

Sempre

Frequentemente

Às vezes

Raramente

Nunca

6. Os não fumadores têm o direito de respirar ar livre de fumo de tabaco:
Concorda completamente
Concorda
Discorda
Discorda completamente
Não sabe / Não responde

Grupo 2:

7. Existe legislação que não permita o consumo de tabaco em determinados locais, em Portugal?
Sim
Não
Não sei

8. Em quais dos locais abaixo mencionados é permitido fumar, por lei, em Portugal? (Assinale todas as respostas que considere correctas)

Recintos desportivos fechados

Espaços de atendimento público

Serviços de saúde

Escolas

Museus

Bibliotecas

Elevadores e similares

Instalações/estações e veículos de transporte público

Estabelecimentos de restauração e bebidas

Estabelecimentos hoteleiros

Estabelecimentos comerciais

Parques de estacionamento cobertos

Lares e instituições para idosos ou pessoas com deficiência 
Estabelecimentos de ensino e outros locais destinados a menores de 18 anos

Salas de espectáculos

Recintos de diversão

Espaços ao ar livre

Todos os acima referidos

Nenhum dos acima referidos

9. Em quais dos espaços fechados abaixo mencionados é permitido fumar, por lei, na UM? (Assinale todas as respostas que considere correctas)

Salas de aula / de estudo / de leitura / de reuniões

Salas de professores

Bibliotecas

Ginásios

Refeitórios

Bares

Átrios

Corredores

Espaços ao ar livre

Áreas fechadas expressamente previstas para o efeito

Todos os acima referidos

Nenhum dos acima referidos

10. A probabilidade de uma pessoa ver o seu estado de saúde prejudicado por fumar é:

Nula

Baixa

Intermédia

Elevada

11. O tabaco é prejudicial para a saúde do fumador se este fumar, por dia:

1-5 cigarros

6-10 cigarros

11-15 cigarros

16-20 cigarros

Mais de 20 cigarros

Todas as anteriores

Nenhuma das anteriores

12. O tabaco é prejudicial para a saúde do fumador se este fumar durante:

1-10 anos

11-20 anos

21-30 anos

Mais de 40 anos

Todas as anteriores

Nenhuma das anteriores

13. O consumo de tabaco provoca dependência?

Sim

Não

14. O consumo de tabaco por uma mulher grávida tem efeitos nocivos para o feto?

Sim

Não

15. Para o não fumador, o fumo do tabaco de outras pessoas: É inofensivo
Causa apenas desconforto

Causa apenas problemas de saúde

Causa desconforto e problemas de saúde

16. A contribuição do fumo do tabaco para a contaminação do ar de espaços fechados é:

Nula

Baixa

Intermédia

Elevada

17. Como classifica o seu conhecimento em relação aos efeitos, benefícios, consequências e outras características do tabaco?

Excelente

Bom

Razoável

Insuficiente

Mau

\section{Grupo 3:}

18. O que pensa do facto de não ser permitido o consumo de tabaco nos espaços fechados da UM?

Concorda completamente

Concorda

Discorda

Discorda completamente

Não sabe / Não responde

19. Considera que a regulamentação de normas de controlo do consumo de tabaco, como a referida no item anterior (pergunta 18) terá como consequência, na maioria dos fumadores, a/o:

Cessação tabágica

Redução do número de cigarros fumados por dia

Aumento do número de cigarros fumados por dia

Ausência de alteração no número de cigarros fumados por dia

20. Considera que, com a proibição de fumar nos espaços fechados da UM, o ambiente nesses locais:

Melhorou muito

Melhorou

Manteve-se igual

Piorou

Piorou muito

Não sabe/não responde

Grupo 4:

21. Alguma vez experimentou consumir tabaco?

Sim

Não

Se assinalou a resposta «não», o preenchimento do questionário termina aqui.

Obrigado pela sua colaboração!

Se assinalou outra resposta, por favor continue o preenchimento do questionário. 
22. Com que idade experimentou, pela primeira vez, consumir tabaco?

$\begin{array}{ll}\text { Antes dos } 12 \text { anos } & 19 \text { anos } \\ 12 \text { anos } & 20 \text { anos } \\ 13 \text { anos } & 21 \text { anos } \\ 14 \text { anos } & 22 \text { anos } \\ 15 \text { anos } & 23 \text { anos } \\ 16 \text { anos } & 24 \text { anos } \\ 17 \text { anos } & \text { Depois dos } 24 \text { anos } \\ 18 \text { anos } & \end{array}$

23. Experimentou consumir tabaco antes ou depois de ingressar na Universidade do Minho (UM)?

Antes

Depois

24. Com que frequência consome tabaco?

Pelo menos uma vez por dia

Pelo menos uma vez por semana

Pelo menos uma vez por mês

Pelo menos uma vez por ano

Menos de uma vez por ano

Se assinalou a resposta «menos de uma vez por ano», o preenchimento do questionário termina aqui.

Obrigado pela sua colaboração!

Se assinalou outra resposta, por favor continue o preenchimento do questionário.

25. No último mês, quantos cigarros consumiu por dia?
0
$1-10$
$11-20$
21-30
31-40

Mais de 40

26. No último mês, quantos cigarros consumiu por semana?
0
$1-10$
$11-20$
21-30
31-40

Mais de 40

\section{Grupo 5:}

27. Fuma em locais públicos fechados?

Sim

Não

28. Em que locais fuma? (Assinale todas as respostas que considere correctas) Em casa

UM
Local de trabalho

Cafés e/ou restaurantes

Bares e/ou discotecas

Todas as anteriores

Nenhuma das anteriores

29. Na UM, costuma fumar em que locais? (Assinale todas as respostas que considere correctas)

Ao ar livre

Corredores e/ou átrios

Bares

Refeitórios

Salas de aula/de estudo/de leitura/de reuniões

Bibliotecas

Instalações sanitárias

Áreas fechadas expressamente previstas para o efeito

Outros

Não fumo na UM

30. Fuma em locais onde não é permitido?

Sim

Não

31. Com que frequência se abstém de fumar na presença de indivíduos não fumadores?

Sempre

Frequentemente

Às vezes

Raramente

Nunca

\section{Grupo 6:}

32. Assinale a opção que melhor caracteriza a sua posição em relação ao seu padrão de consumo de tabaco neste momento: Nunca pensou em deixar de fumar

Já pensou em deixar de fumar, mas nunca tentou Já tentou deixar de fumar, mas sem sucesso Está actualmente a tentar deixar de fumar Já deixou de fumar e actualmente não fuma

\section{Grupo 7:}

33. Agora que na UM não é permitido o consumo de tabaco nos espaços fechados, que comportamento tem adoptado?

Continua a fumar nos locais fechados

Fuma às escondidas nos locais fechados

Fuma apenas ao ar livre

Deixou de fumar na UM

34. Agora que na UM não é permitido o consumo de tabaco nos espaços fechados, o seu consumo:

Cessou

Diminuiu

Manteve-se

Aumentou

\section{Obrigado pela sua colaboração!}

